Viso - Cadernos de estética aplicada

Revista eletrônica de estética

ISSN 1981-4062

№ 5, jul-dez/2008

http://www.revistaviso.com.br/
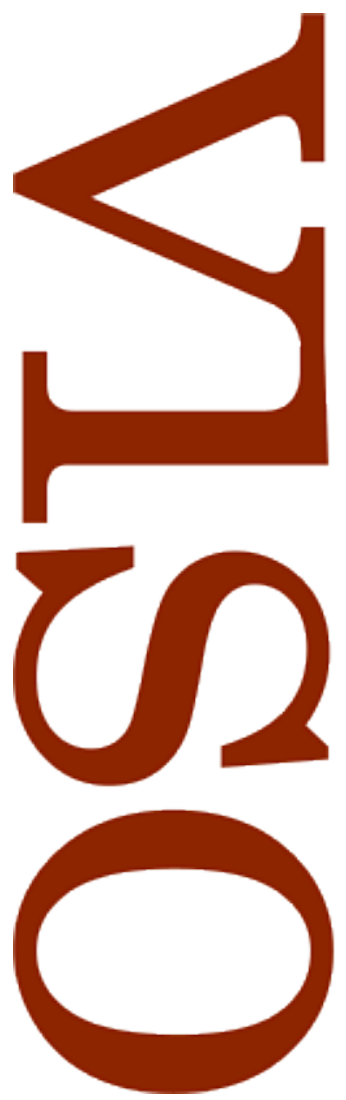

\title{
Melhor do que o silêncio: o show e a música de João Gilberto Pedro Duarte
}

Pontifícia Universidade Católica do Rio de Janeiro (PUC-Rio)

Rio de Janeiro, Brasil 


\section{RESUMO}

Melhor do que o silêncio: o show e a música de João Gilberto

Este artigo foi escrito após o show de João Gilberto apresentado no dia 24 de agosto de 2008, no Teatro Municipal do Rio de Janeiro. Narrando os acontecimentos do show, o artigo elabora sua interpretação sobre o procedimento artístico de João Gilberto. Sua abordagem, contudo, não é a da crítica musical técnica, mas, antes, a de certa crítica da cultura com viés filosófico.

Palavras-chave: João Gilberto - diferença - repetição - silêncio - Brasil

\section{ABSTRACT}

Better than silence: João Gilberto's concert and music

This article was written after the show presented by João Gilberto on August 24, 2008, at the Teatro Municipal of Rio de Janeiro. In discussing the show, the article describes an interpretation of João Gilberto's artistic process. The approach, however, is not through a critique of musical technique, but rather through a criticism of culture with philosophical bias.

Keywords: João Gilberto - difference - repetition - silence - Brazil 


\section{DUARTE, P. "Melhor do que o silêncio: o show e a música de João Gilberto". In: Viso: Cadernos de estética aplicada, v. II, n. 5 (jul-dez/2008), pp. 1-15.}

DOI: 10.22409/1981-4062/v5i/61

Aprovado: 27.10.2008. Publicado: 29.12.2008.

(C) 2008 Pedro Duarte. Esse documento é distribuído nos termos da licença Creative Commons Atribuição-NãoComercial 4.0 Internacional (CC-BY-NC), que permite, exceto para fins comerciais, copiar e redistribuir o material em qualquer formato ou meio, bem como remixá-lo, transformá-lo ou criar a partir dele, desde que seja dado o devido crédito e indicada a licença sob a qual ele foi originalmente publicado.

Licença: http://creativecommons.org/licenses/by-nc/4.0/deed.pt_BR

Accepted: 27.10.2008. Published: 29.12.2008.

(C) 2008 Pedro Duarte. This document is distributed under the terms of a Creative Commons Attribution-NonCommercial 4.0 International license (CC-BY-NC) which allows, except for commercial purposes, to copy and redistribute the material in any medium or format and to remix, transform, and build upon the material, provided the original work is properly cited and states its license.

License: http://creativecommons.org/licenses/by-nc/4.0/ 
Show de música, principalmente, eu tenho o maior desânimo de ir. Há filas demais, todos aqueles fãs uniformizados de classe média contente. E a maior parte dos shows é apenas um disco cantado ao vivo. O caso do João Gilberto é diferente. JG é um cara que se valoriza pelo silêncio, as pouquíssimas apresentações e os discos, muito selecionados. Quer dizer, ele se valoriza também pelo que não faz, os shows que não dá. E quando se dispõe a cantar em público, é um acontecimento que vem com muito peso. O mesmo peso que ele dá a cada nota musical.

Sérgio Sant'Anna, "O concerto de João Gilberto no Rio de Janeiro".

"Nada parecia ter mudado em João Gilberto, exceto a voz e o violão, mas o Rio de Janeiro, sem saber, estava lidando com outro homem". ${ }^{1}$ Foi com essas palavras que Ruy Castro, ao contar a história da bossa nova, narrou o retorno de João Gilberto ao Rio após a primeira e fracassada tentativa na cidade. Desta vez, depois de gravar o famoso violão nas faixas "Chega de saudade" e "Outra vez" do disco Canção do amor demais, de Elizete Cardoso, João, finalmente, seria notado. Daí pra frente, veio a parceria com Tom Jobim e, de resto, o encanto que tomaria, um a um, os músicos e os cidadãos cariocas. Era o já distante ano de 1958.

Eis que, cinqüenta anos depois, no dia 24 de agosto de 2008, João Gilberto entrava no palco do Teatro Municipal do Rio de Janeiro. Se a cidade, em 1958, lidava com "outro homem", não resta dúvida, pelo furor em torno do show de 2008, que ela o acolheu definitivamente. Era evento raro, pois suas apresentações tornam-se cada dia mais escassas. Tudo foi cercado de muita pompa. Não faltaram as filas de horas para comprar os ingressos e nem os inúmeros convidados que deixaram muitos daqueles que estavam nas ditas filas sem lugar. Em três horas, os cerca de mil e quinhentos ingressos à venda esgotaram-se. Nos jornais, a reincidência da figura de João Gilberto contrastava com sua habitual reclusão. Era tanta badalação antes e depois do show que, se não fosse pelo durante, talvez ninguém notasse que algo cuja essência passa incólume por todo este estardalhaço do entretenimento acontecera. Mas aconteceu.

Foi com a mesma delicadeza de sempre que, ao entrar no palco, passos lentos, carregando o próprio violão, João Gilberto, em sua impecável discrição, sem esforço, tomou as rédeas do que se passava, amansando o que estava ao seu redor. Todo o aturdido zunido das pessoas conversando sem parar entre si - como se tornou regra antes de apresentações artísticas - calou. De súbito, fez-se silêncio - ainda, àquela altura, em certo clima reverencial. Mas logo se mostrou que não era apenas a mitificação que implantava o silêncio. Era a sua música.

No meio do suntuoso Municipal, do exagero das falas, das roupas e das fotos, dos celulares e dos olhares, surgiu aquele homem de terno e gravata, sóbrio, quase um monge, devagar e calmo sobre o palco. Foi assim que, já em sua primeira música, mudou tudo. Reorganizou o espaço, que agora tinha ponto focal. Parecia que todos irradiavam dali, dele, como se linhas invisíveis - nossos olhares, na verdade - nos 
ligassem até aquele homem. Sozinho, por detrás da aparente fragilidade, ele se impunha. No ritmo de suas canções, era o ritmo da vida mesma que se refazia. Não havia mais tempo para a falta de tempo e nem espaço para a dispersão. Estava tudo concentrado, focado, centrado.

É curioso como João Gilberto reproduz, no ambiente do show, o que fez com a história da música brasileira. Ele reorganiza tudo, absorve, transforma, realoca e, com isso, desloca para outro patamar. Lembra o que Hegel chamava de suprassumir, que quer dizer superar e conservar ao mesmo tempo, mas o faz sem, aparentemente, precisar negar nada. João Gilberto faz esta torção do movimento dialético, pelo qual transforma tudo o que havia antes, na música brasileira e no lugar em que faz seu show, mas sem excluir ou aniquilar.

Já no volume com o qual canta, que parece testar o limite da escuta, para ver quão baixo é possível ir e ainda ser ouvido, João Gilberto nos leva para sua terra. É muito comentado que a bossa nova nasceu na zona sul do Rio em apartamentos da classe média, ou seja, em ambiente doméstico, em rodas de amigos. Ela carrega este intimismo. Mas o impressionante é que, para além da empiria, a música de João reduz o Teatro Municipal às dimensões de uma casa, de uma pequena sala na qual ele canta baixo para alguns milhares de amigos, que precisam então silenciar para ouvi-lo.

No show, esta mutação é como um choque às avessas, em que nos é tirada a eletricidade a que estamos habituados. Do exagero ao mínimo. Do excesso ao pouco. Da dispersão à precisão. Somos colocados em outra voltagem, mais baixa e íntima, porém mais intensa. João Gilberto nos arranca do turbilhão em que estávamos e nos lança em sua tão famosa simplicidade: voz e violão. Nada mais. Só ele, sua voz, seu violão. Dizendo assim, parece até que são três coisas, quando, na verdade, são uma só. É por isso que João Gilberto não pode ter acompanhamento. Pois só ele compreende seu violão e só o seu violão o compreende.

Dado o início do show, só restava acompanhá-lo escutando. Sua voz está mais grave porque traz em si, no corpo e no espírito, a gravidade da própria vida. Se a força da gravidade é aquilo que faz pesar, João Gilberto não se recusa a ela. Pelo contrário. Ele se desenvolve nela. Ela é seu meio, seu modo de estar. Sua música, por mais leve que seja, pesa na balança da vida. Na sua figura envelhecida de 77 anos, aparece a história da persistência do homem na abertura da relação com o ser, na qual tudo se faz e se desfaz. Daí nasce sua máxima atenção, que não deixa espaço para o erro.

Sua relação com a música é tão desprovida das injunções menores a que estamos acostumados, sejam elas do mercado ou do profissionalismo burocrático, que provocam estranheza. "João Gilberto é assim: fica sempre no limite entre o esquisito e o genial"2, escreveu um colunista após o show. Ele tem razão. Mas, a rigor, o genial, por definição, 
fica sempre no limite do esquisito, já que é justamente o que foge à regra da normalidade, em contraste com a qual dizemos que alguma coisa é esquisita. Só que João Gilberto não é genial porque é esquisito. Ele é esquisito porque é genial.

Foi dessa ordem o início do show, quando, depois de cantar "Você já foi à Bahia?", do então recém falecido Dorival Caymmi, João Gilberto, após os aplausos do público, atacou de "Você já foi à Bahia?". Isso mesmo, de novo. Era a velha procura pela perfeição, a obstinação para achar a forma mais bem acabada. Logo de cara, éramos convidados a partilhar a aventura da vida e da arte de João Gilberto em um só show. Nela, não há lugar para a preocupação com a "perda de tempo" que aparentemente é repetir a mesma música duas vezes seguidas, gesto de ousadia de dar inveja a qualquer roqueiro que quebra guitarras por aí. Se para a lógica produtiva do capitalismo esta repetição é desperdício e para os modismos em voga é monotonia, para João ela é apenas necessária. Só contam, para ele, a arte e sua criação. "João Gilberto é a nota musical, o som. Ele só existe nesta medida". ${ }^{3}$

Repetindo tantas vezes a pergunta que dava título à música que abriu o show, era quase como se João a colocasse, metaforicamente, sobre nós.

Você já foi à Bahia, nêga?

Não? Então vá!

Mas os nêgos, no caso do show, éramos nós. E a Bahia, no caso, era ele, João, baiano de Juazeiro. Nunca ouvistes João, nêgo? Não? Então ouça. Mas é claro que já ouvimos quase todas as músicas que João canta. E, no entanto, nunca as ouvimos, nunca ouvimos como elas estão ali, ao mesmo tempo elas e outras, já que nunca chegam iguais. É que João é único na sua criação através da recriação das canções. Nele, elas se transformam a cada vez. Pois ele tem um jeito que nenhum cantor tem, assim como a Bahia, descrita no fim da música por Caymmi.

A Bahia tem um jeito

Que nenhuma terra tem

Daí a fundamental radicalidade de repetir a mesma música logo em seguida, como se nos avisasse: vocês ainda não a ouviram, a despeito de a conhecerem. Prestem atenção, pois aqui é o reino das sutilezas nas quais eu, João, vivo - e onde a própria vida se faz em mim. E aquilo que parece esquisito de fato o é, na medida em que não compartilha da normalidade, nos forçando, com afeição, em outra direção. Este início do show apresentava, numa cápsula, a estrutura com a qual teríamos que lidar dali em diante: repetição e diferença, música e silêncio. Para João, os opostos se fazem um pelo outro, ao invés de se excluírem. 
Emendando música atrás de música, retido no teor de trabalho que é o seu, João Gilberto mal dava espaço para as manifestações de agradecimento que o público, no entanto, fazia mesmo assim, aplaudindo cada música. Nestes breves intervalos, ele permanecia quase paralisado, olhar para o chão e braço sobre o violão, esperando apenas para engatar a próxima música. Enquanto isso, as pessoas, alimentadas pelo medo que a fama de João promove, aproveitavam este momento para se ajeitarem na cadeira, já que qualquer som durante o show é ameaça de abandono do palco por parte do artista.

Era impressionante. Nenhuma fala dele para o público, nenhuma pausa para comentários ou apresentações, nenhuma espirituosidade bem sacada, como seria do gosto contemporâneo. Timidez? Talvez. E concentração, muita concentração. Mas, sobretudo, João Gilberto, com isso, mais uma vez no domínio da situação, não nos permite a conversa lateral, o riso frouxo. Não deixa espaço para que escapemos da intensidade que ele, parecendo sugerir, impõe delicadamente. É impossível, no show, fugir da sua criação, da sua música. Ele bloqueia, em sua retitude absoluta, os becos em que buscamos nos esconder para nos proteger, por não suportarmos que é aquilo mesmo, e que aquilo é tudo.

Dois murmúrios apenas aconteceram, além da série de músicas. No primeiro, João mencionou Caymmi, sublinhando a adequação entre letra e melodia no mestre. Nunca é demais ressaltar a importância de Caymmi para João. E não apenas pelas tantas músicas que dele gravou. É que, como ressaltou Caetano Veloso, "o grande esforço de modernização de João se apoiou na modernização sem esforço de Caymmi”. Mais ainda, Caymmi orienta "o caráter normativo geral, a hegemonia estética do estilo de João". ${ }^{4}$ É que neles a palavra cantada preserva a espontaneidade da fala, mas, mesmo assim, sendo dotada de rigor sem precedentes. Palavras e notas tão precisas mas, ao mesmo tempo, carregadas pelo balanço de rede baiano, tranqüilo e natural.

Nesse sentido, a herança de Caymmi encontrou em João a perseguição do sonho da arte moderna, nascido com o romantismo, de juntar prosa e poesia, dando à fala cotidiana a magia da arte e, ao mesmo tempo, vitalizando esta com o vigor daquela. Isso é levado, em João, até o radicalismo de não sabermos bem distinguir onde está uma e onde está outra.

Essa maravilhosa prosa é prosa, e, no entanto, é poesia. Sua riqueza é graciosa, sua simplicidade, significativa e profunda, e seu nobre e delicado desenvolvimento sem rigor desnecessário. Mesmo que as linhas mestras deste estilo sejam, no todo, tiradas do discurso social culto da vida, ele também toma parte em metáforas raras e estranhas que possuem como objetivo estabelecer uma relação entre o mais alto e puro, de um lado, e alguns aspectos peculiares a este ou àquele jeito de falar cotidiano, ou àquelas esferas que, de acordo com o senso-comum, são muito distantes da poesia. ${ }^{5}$ 
Essas palavras não foram escritas, pelo menos não originalmente, para descrever a criação de Dorival Caymmi ou de João Gilberto. Ela foram escritas mais de duzentos anos atrás, pelo pensador romântico Friedrich Schlegel para falar de Goethe. E, no entanto, não deixam de fazer sentido quando pensamos no maior expoente de nossa música moderna - o que dá a dimensão da profundidade com que ele tocou no cerne da tradição estética ocidental e de seus desafios.

Mas, voltando ao show, houve ainda mais um murmúrio no meio das músicas encadeadas uma atrás da outra. Do mesmo modo que o primeiro, ele foi bem breve. Dava conta de antigas amizades: com Tito Madi e Sérgio Ricardo, de quem cantou, respectivamente, "Chove lá fora" e "O nosso olhar", peças raras em seu repertório. E foi só: esses dois rápidos murmúrios, em tom de voz baixíssimo, foram tudo que aconteceu além de música atrás de música. Pois isto é tudo.

É aí que se decide a vida, para João. E o resto é apenas o resto. Seu repertório permanece basicamente o mesmo. Nisso, ele lembra Mário Reis, como apontaram os vanguardistas paulistas da poesia concreta, em especial Augusto de Campos. Encontramos, "nos dois casos, a obsessiva fidelidade a um mesmo repertório sempre revisitado e que cresce a conta-gotas", lembra Caetano Veloso. "Desafinado", "Garota de Ipanema", "Meditação", "Lígia", "Retrato em branco e preto"... Foram esses e outros "clássicos" que compuseram aquele que talvez tenha sido o último show de João Gilberto na sua cidade.

Mas é verdade que fomos presenteados com algumas surpresas, além das músicas de Tito Madi e Sérgio Ricardo. João cantou “13 de ouro", tirada de 1949, do conjunto vocal Anjos do Inferno (ele mesmo, aliás, foi crooner de conjunto vocal no início da carreira). Sua letra gracejeira, de Herivelto Martins e Marino Pino, levou o público a risadas, ainda que discretas. Também ouvimos o "Samba do avião", de Tom Jobim, que, ao contrário de outras canções do autor, não conta entre as mais freqüentadas por João. Tom, aliás, foi presença marcante no repertório.

Terminado o show, João Gilberto se retirou na mesma toada que entrou. Mas o público não se contentou. Sob aplausos, João Gilberto retornou. Estava mais leve, mais descontraído. Era o bis. Mas não o bis normal que conhecemos, pois foram cerca de trinta minutos de música em que o clima mudara. Nele, aconteceu o momento alto do show, para muitos. Durante "Chega de saudade", o público ousou acompanhar João. Por conta de sua fama, o canto das pessoas era sussurrado, já que todos sabiam o quanto poderiam irritá-lo a desafinação e a desconsideração com o fato, como já disse certa vez, de que vamos até lá para escutá-lo. Mas este medo prévio foi a condição de possibilidade para a beleza do momento, pois obrigou as vozes a conviverem com o entusiasmo mediadas pela contenção, já que qualquer aumento do som - era óbvio engoliria o canto já baixo de João Gilberto. Foi assim que aquelas poucas milhares de 
bocas se abriram, mas não muito, para, bem baixinho, cantarolar, no Teatro Municipal, "Chega de saudade", acompanhando João Gilberto, mas sem atrapalhá-lo.

No fim daquele momento, ao contrário das expectativas, João Gilberto comentou, olhando para o público, que gostara do "sussurrozinho". Se sussurro já é baixo, imaginem no diminutivo. E esta foi a beleza da coisa. João pediu, então, que fosse repetido, que ele cantaria de novo "Chega de saudade" para ser acompanhado. Liberados do temor prévio e engajados na surpreendente tarefa solicitada, as pessoas abandonaram a contenção, aumentaram a voz e cantaram o clássico da bossa nova. Não foi tão bonito quanto da primeira vez. Mas João Gilberto soube lidar, inteligentemente, com a subida de voz do público. Ele abdicou de cantar, apenas ficou nas batidas de violão e em brincadeiras vocais diante da música. Tudo banhado em enorme bom-humor.

Mais falante do que na primeira parte da apresentação, o que não era difícil, João Gilberto arregaçou a manga direita da camisa e parecia se sentir mais à vontade com a exposição de si no show. Fez questão, então, de destacar Os Cariocas como "os professores de música no Brasil". E atacou de "Tim tim por tim tim", de Geraldo Jacques e Haroldo Barbosa, em divertida alusão ao modo de cantar do grupo vocal, deixando de lado seu jeito mais próprio. Era visível a satisfação de João Gilberto com aquele momento, com o show que fazia.

Se o show teve lá suas surpresas agradáveis, elas não escondem, contudo, que a novidade de João Gilberto aparece ainda mais nas velhas músicas, que em geral já conhecemos. "Em seu violão e no seu canto, ele exerce a prática do absoluto, numa linguagem que se impõe rígida como um monolito", escreveu o crítico Leonardo Lichote, atentando, contudo, para o fato de que se trata de "um absoluto cambiante". ${ }^{7}$ João, em sua figura mesma no show, já transmite algo deste absoluto, impecável em sua discreta elegância. Mas é na música que ele se revela, quando, no caráter cambiante pelo qual trabalha o mesmo repertório, o absoluto da criação aparece.

Ninguém que vai ver João Gilberto, aliás, espera outra coisa. Entretanto, se isso significar apenas o gosto pela segurança, nada feito. Pelo menos não para quem soube escutar o show de João Gilberto. Pois, para ele, é no ato mesmo da repetição que sobrevém a diferença, como foi possível ver, por exemplo, em "Disse alguém", versão de "All of me", que conhecemos primeiro através do jazz de Billie Holiday. Na voz e no violão de João Gilberto, tem-se a impressão de que nunca uma música é igual a outra, aliás, tem-se a impressão de que nunca uma música é sequer igual a si mesma.

Ele não é mais um desses casos de artistas que vivem deitados sobre a obra e a fama que construíram. Não existem nem obra e nem fama para João Gilberto. Só o trabalho e a vida - a música. Por isso, nada é mais equivocado do que diluí-lo no anedotário em 
torno de sua biografia, como é de costume. Parece mais, aliás, que este gesto, que narra os incontáveis casos insólitos de sua vida, nasce da impossibilidade de suportar a força essencial de sua criação. Reduzimos, assim, sua radicalidade à mania, sua insistência à obsessão psicológica, seu esforço à idiossincrasia. Seria suficiente, neste como em outro casos, lembrar do comentário de Merleau-Ponty: "esta obra a fazer exigia esta vida". ${ }^{8}$ E só isso.

João Gilberto faz o mesmo pois o mesmo é o que ele faz. Mas a cada vez que o faz, faz diferente. Eis o lance: sua persistência, que é bem distinta da mera teimosia. João Gilberto é como Amílcar de Castro. É como Pollock. Nisso, também recebeu algo do melhor jazz norte-americano. No final de seu livro O último round, Julio Cortázar cita Miles Davis comentando, sobre John Coltrane, que "o que ele faz é tocar cinco notas e ficar improvisando em torno delas para ver de quantas maneiras diferentes isso pode soar". 9

João Gilberto, embora por via distinta, também se dedica a esta exploração da riqueza de possibilidades que as mesmas músicas contêm, fazendo ver que, no que consideramos pouco, pode haver muito. Ele não expande quantitativamente, pois sabe que este é o jeito mais rápido de afrouxar e se diluir. Ele expande qualitativamente, pela precisão e pelo rigor. Não larga aquelas poucas músicas pois elas sempre parecem poder dar mais. Só que este mais, em geral, é menos. Elas podem ser ainda mais concisas e diretas, podem ser levadas a um grau ainda maior de concentração de força. Esta "limpeza e a enxutez de João Gilberto foram aprendidas com Caymmi, vêm dele" ${ }^{10}$, lembra, mais uma vez, Caetano Veloso.

Por um lado, João mostra, com isso, que o muito que temos todos os dias pode ser bem pouco. E que o pouco que, não raro, desprezamos pode ser, ele sim, muito. Não é na oferta incessante de opções que nos dá o liberalismo que está a liberdade, mas em algo bem menos evidente e mais íntimo, ao mesmo tempo mais simples e mais rico. É no mesmo, naquela retomada incessante e infinita do mesmo, que João Gilberto encontra a chance de implementar e compreender as diferenças. Pois só sob o pano de fundo do mesmo é que as diferenças se destacam. Se não, são apenas dispersão, onde tudo se move sem parar e sem folga, na qual nos acostumamos a viver e nos regozijar.

Leonardo Lichote, ao escrever sobre o show de João Gilberto dias antes em São Paulo, percebeu em detalhe este movimento pelo qual o mesmo parece ser a fonte de onde jorram as diferenças.

Nos clássicos, fica mais evidente a força de suas recriações. Em "Wave", o deslocamento entre melodia (voz) e harmonia (violão) dá outro colorido às suas notas. "Meditação" foi quase recitada, em versos como "E perdeu a paz". "Corcovado" teve trechos cantados também quase em tom de fala, como se as notas estivessem mais próximas. Em alguns momentos de "Caminhos cruzados", João deixava de lado sua batida e fazia ataques únicos às cordas, acorde por acorde, como para evidenciar a riqueza do desenho que estava traçando - o efeito foi usado também em "Lígia" (onde 
suprimiu alguns "nuncas" da letra, além do nome da musa) e "Você já foi à Bahia?", entre outras. "Morena boca de ouro" ganhou balanço especial nos versos "Roda morena vai não vai / Ginga morena cai não cai / Samba morena e me desacata" - era a representação musical do gingado da moça. O mesmo aconteceu em "Rosa morena" e "Garota de Ipanema", moças que tiveram o andar filtrado por João. ${ }^{11}$

Somente porque aquelas mesmas canções continuam ali, João Gilberto pode exercitar a arte da imprevisibilidade. Pois nunca sabemos como elas vão ser. Muda uma palavra aqui, uma descontinuidade ali, uma acelerada acolá, uma atrasadinha mais adiante. E pronto: foi o mundo todo que, naquela finura de tom, reverberou na sua multiplicidade interior. Para João Gilberto, a diferença é força centrípeta, de penetração, de aprofundamento, e não, como geralmente pensamos, centrífuga, voltada para fora. Ele já tem tudo o que precisa para que precise de tudo.

Muitas vezes já se disse que a bossa nova "não constituiu um gênero de música, mas uma maneira de tocar". ${ }^{12}$ É em parte verdade. Mas se João Gilberto não inventou um gênero é porque ele reinventou tudo - e não cessa de reinventar. Sua profundidade simples ou sua simplicidade profunda é que ele não se deixa julgar pelo critério de criatividade que lhe é extrínseco, pois, em sua música, redefine nosso próprio critério do que seja a criação. Ela deixa de ser, para João Gilberto, a mera ruptura com aquilo que veio antes e passa a ser a capacidade de absorver em si o que veio antes, mas não como mera repetição, e sim como recriação, capaz, até, de nos fazer enxergar nesse passado elementos nos quais nunca reparamos. Esta acolhida, contudo, é feita com tal perfeição em seu resultado final que, muitas vezes, nem percebemos a operação complexa que aí esteve envolvida.

João Gilberto, com sua interpretação muito pessoal e muito penetrante do espírito do samba, a qual se manifestava numa batida de violão mecanicamente simples mas musicalmente difícil por sugerir uma infinidade de maneiras sutis de fazer as frases melódico-poéticas gingarem sobre a harmonia de vozes que caminhavam com fluência e equilíbrio, catalisou os elementos deflagradores de uma revolução que não só tornou possível o pleno desenvolvimento do trabalho de Antônio Carlos Jobim, Carlos Lyra, Newton Mendonça, João Donato, Ronaldo Bôscoli, Sérgio Ricardo - seus companheiros de geração - Roberto Menescal, Sérgio Mendes, Nara Leão, Baden Powell, Leny Andrade -, como deu sentido às buscas de músicos talentosos que, desde os anos 40, vinham tentando uma modernização através da imitação da música americana - Dick Farney, Lúcio Alves, Johnny Alf, o conjunto vocal Os Cariocas -, revalorizando a qualidade de suas criações e a legitimidade de suas pretensões (mas também driblando-os a todos com uma demonstração de domínio dos procedimentos do cool jazz, então a ponta-de-lança da invenção nos Estados Unidos, dos quais ele fazia um uso que the permitia melhor religar-se ao que sabia ser grande na tradição brasileira: o canto de Orlando Silva e Ciro Monteiro, a composição de Ary Barroso e Dorival Caymmi, de Wilson Batista e Geraldo Pereira, as iluminações de Assis Valente, em suma, todo um mundo de que aqueles modernizadores se queriam desmembrar em seu apego a estilos americanos já meio envelhecidos); marcou, assim, uma posição em face da feitura e fruição de música popular no Brasil que sugeria programas para o futuro e punha o passado em nova perspectiva - o que chamou a atenção de músicos eruditos, poetas de vanguarda e mestres de bateria de escolas de samba. ${ }^{13}$ 
Esta longa, porém concisa, passagem de Caetano Veloso mostra de que modo a posição de João Gilberto na história da música brasileira, ao se fundar, refundou toda esta história, modificando nossas imagens de seu passado e nossas expectativas quanto ao seu futuro. Seu "incontestável pioneirismo" ${ }^{14}$, nesse sentido, tem alcance maior do que às vezes se imagina. Todas as influências que nele se exerceram, fizeram-se sob o crivo da criação singular. Daí a capacidade de canalizar tantas águas diferentes, no tempo e no espaço, num mesmo rio. Novas perspectivas eram criadas por João Gilberto, para trás e para a frente, pela sua reinvenção da música brasileira.

Em seu show, esta amplitude se torna viva, absorvendo, com simplicidade inacreditável, toda esta complexidade histórica de sua criação. João Gilberto não demanda erudição, mas atenção. Em seu show, a emoção não carece de conhecimento prévio, mas de abertura e escuta, de sensibilidade e inteligência. Bastam elas para que ele revele tudo que pode dar em sua arte. Nós vemos e ouvimos sua recriação nas variações infinitas que promove das canções - sem inventar quase nada, mas reinventando quase tudo.

Daí a sensação prazerosa de que mesmo aquelas músicas já desgastadas pela sua disseminação incessante e pela sua decodificação já caída na obviedade ganham nova vida quando tocadas e cantadas por João Gilberto. Mesmo "Garota de Ipanema", durante o show, parecia ser apresentada ali como se fosse a primeira vez. Por trás da serenidade da bossa nova, perpassa, no show de João Gilberto, esta energia de vida de alguém que tem algo a dizer, que tem algo a fazer.

Na época de nascimento da bossa nova, a operação que João Gilberto fazia na música refletia os esforços da arte brasileira de integração não subserviente ao mundo ocidental, que então já caminhava a passos largos na sua modernização urbana e industrial. Do mesmo modo que a seleção de Pelé e Garrincha mostraria ao mundo nas Copas de 1958 e 1962 que eficiência e rigor modernos não precisavam aniquilar a juventude e a alegria, João Gilberto, na sua música, vinculava, harmoniosamente, o esmero técnico ao clima amadorístico, marca da nova bossa.

Era música feita entre amigos, produzida nas relações cujo elo era o coração, não a profissão. Nisso se anunciava a possibilidade de que o "homem cordial" brasileiro, tematizado por Sergio Buarque de Holanda, não fosse apenas estorvo ao projeto civilizacional moderno, por impedir a burocratização formal e impessoal das relações e colocar, ao invés disso, o coração em seu centro. Pelo contrário, daí poderia surgir a perfeição que nem mesmo o capitalismo de mercado exige.

João Gilberto, através de sua música, reinventava a possibilidade de destino da cultura do país, reabilitando seu passado e o colocando dentro da perspectiva do futuro moderno, sem preconceitos com o que vinha de fora justamente porque não o macaqueava, mas o recriava. Embora internamente a música de João Gilberto esteja 
mais próxima do samba baiano do que do carioca, sua criação se enraíza no jogo de cintura do Rio de Janeiro, cujo espírito cosmopolita era propício a deixar de lado a "angústia da influência" e combinar livremente as mais diversas fontes de inspiração.

Na sua convivência entre balneário festivo e capital produtiva, entre o afeto e o trabalho, o Rio encontrou na bossa nova a sua música moderna, do mesmo modo que encontraria sua vocação artística no Neo-concretismo, que submetia o rigor racional concreto paulista à flexibilidade carioca, mas sem jogá-lo fora. João Gilberto representa o esplendor deste momento da cultura nacional em termos musicais, acenando para o possível casamento entre a ética do trabalho e a criação lúdica. Na música de João Gilberto, "a dimensão afetiva das palavras supera a funcional em exatidão e em capacidade propositiva" ${ }^{\prime 15}$, observou Lorenzo Mammi, apontando aí o teor utópico da bossa nova.

Para nós, hoje, importa que a bossa de João continua ainda nova, a despeito das décadas já passadas desde seu surgimento. E não apenas pela modernidade do seu jeito, mas porque ela não foi abandonada à sua própria sorte. Desde sempre, como observa Zuza Homem de Mello, ela "não era uma sistematização imutável"16 para João Gilberto, não era um padrão. Era forma, não fôrma. Sua bossa, ainda tão nova, o é porque continua sendo, ainda, o que era: criação.

Esta criação, para João, se dá nas reapropriações e retomadas, nas quais ele se faz e se refaz. Sempre de novo, sempre novo. Não precisa de marco zero algum, como gostariam os modernistas, embora faça, a seu modo próprio, certa antropofagia, como queria Oswald de Andrade. Luiz Tatit notou bem que, a despeito do caráter revolucionário que representa a música de João Gilberto, ele "jamais escondeu sua atração pela linguagem de seus antepassados e, mais precisamente, pela gramática construída passo a passo durante a primeira metade do século". ${ }^{17}$ Foi só por isso, aliás, que pôde lidar com tal herança com tanto discernimento e inteligência, identificando seus elementos e formas peculiares, de maneira a superá-la ao mesmo tempo em que a conservava. É que para ele só interessava conservá-la de modo vivo, ou seja, não pela mera repetição - o que demandava a superação criativa.

Por isso, a novidade de João Gilberto não abandona suas canções jamais, pois não carece disso para que seja nova. Em cada traço de João, renova-se a percepção de Walter Garcia, em seu ótimo livro sobre ele: trata-se da "contradição sem conflitos". ${ }^{18}$ Para João Gilberto, o velho e o novo não se opõem, mas podem se unir na constituição amorosa da atividade criativa. É no meio mesmo de tudo o que há que se fez e se faz João Gilberto. No eterno retorno do mesmo, surge a diferença, já que, só por ser retorno, já não se trata, rigorosamente, do mesmo. Diferença e repetição, como queria Deleuze. ${ }^{19}$ Foi assim que "esse 'João de nada' fez tudo: ensinou voz e música ao mundo" ${ }^{20}$, como disse Augusto de Campos. 
Este movimento da própria vida é que dá o tom, não apenas musical, da arte de João Gilberto. Ele precisa, a cada vez, inventar o novo dentro do antigo e, assim, criar a própria história em cada presente que se dá. Para apenas repetir o mesmo ou se dispersar nas diferenças, melhor calar. João só abre a boca quando tem algo a dizer. Por isso não tem muitas músicas nem dá tantos shows. Sua economia formal é também ética, nesse sentido. Sua leveza não é caprichosa nem arbitrária. Ela é exigida porque em jogo está a mais delicada das fronteiras, em que, diante do abismo do ser, o homem rompe o silêncio com a sua fala poética.

Todo escritor conhece a angústia da página em branco. João Gilberto parece, a cada dia, viver mais intensamente esta angústia, que, no seu caso, é a de furar o silêncio com o som. Daí a dificuldade. Daí a gravidade. Daí a precisão necessária. Daí a perfeição, mesmo que nunca acabada. De tanto limpar, João parece ir até o fundo do silêncio das coisas, mas apenas para deixar aí seu som aparentemente mínimo - que é na verdade o máximo que o silêncio permite. Por isso, "melhor do que o silêncio só João", como cantou Caetano Veloso.

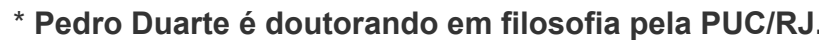

Deixo, desde já, meus agradecimentos ao Paulo da Costa de Oliveira, cujas indicações bibliográficas foram preciosas para a elaboração deste artigo, bem como suas próprias linhas escritas sobre João Gilberto. E dedico as minhas linhas aqui, por sua vez, à Maria Borba, grande amiga que, além de sugerir algumas idéias sobre o show de João Gilberto, partilhou o amor por sua música comigo.

${ }^{1}$ CASTRO, R. Chega de saudade. São Paulo: Companhia das Letras, 1990, p. 158.

${ }^{2}$ XEXÉO, A. “Miss Simpatia no Teatro Municipal”. In: O Globo, 27/08/2008.

${ }^{3}$ SANT'ANNA, S. "O concerto de João Gilberto no Rio de Janeiro". In: Contos e novelas reunidos. São Paulo: Companhia das Letras, 1997, p. 303.

${ }^{4}$ VELOSO, C. Verdade Tropical. São Paulo: Companhia das Letras, 1997, p. 222.

${ }^{5}$ SCHLEGEL, F. "Über Goethes Meister". In: Kritische Schriften. München: Carl Hanser, 1970, p. 459

${ }^{6}$ VELOSO, C. Op. cit., p. 226.

${ }^{7}$ LICHOTE, L. “João, absoluto”. In: O Globo, 16/08/2008.

${ }^{8}$ MERLEAU-PONTY, M. "A dúvida de Cézanne”. In: Textos escolhidos. São Paulo: Abril Cultural, 1980, p. 122.

${ }^{9}$ CORTÁZAR, J. O último round - tomo II. Rio de Janeiro: Civilização Brasileira, 2008, p. 288.

${ }^{10}$ VELOSO, C. Op. cit., p. 223.

${ }^{11}$ LICHOTE, L. Op. cit.

12 TINHORÃO, J. R. Pequena história da música popular. Petrópolis: Vozes, 1974, p. 221.

${ }^{13}$ VELOSO, C. Op. cit., pp. 35-37.

${ }^{14}$ TINHORÃO, J. R. Op. cit., p. 224. 
${ }^{15}$ MAMMI, L. "João Gilberto e o projeto utópico da bossa nova". In: Novos Estudos Cebrap, n. 34 (nov., 1992), p. 70.

${ }^{16}$ HOMEM DE MELLO, Z. João Gilberto. São Paulo: Publifolha, 2001, p. 26.

17 TATIT, L. Todos entoam: ensaios, conversas e canções. São Paulo: Publifolha, 2007, p. 34.

${ }^{18}$ GARCIA, W. Bim bom: a contradição sem conflitos de João Gilberto. São Paulo: Paz e Terra, 1999.

${ }^{19}$ DELEUZE, G. Diferença e repetição. Rio de Janeiro: Graal, 1988, p. 16.

${ }^{20}$ CAMPOS, A. Balanço da bossa e outras bossas. São Paulo: Perspectiva, 2005, p. 57. 